\title{
The school-tertiary interface in mathematics: teaching style and assessment practice
}

\author{
Michael O. J. Thomas • Sergiy Klymchuk
}

Received: 6 June 2011 / Revised: 22 February 2012 / Accepted: 2 August 2012 /

Published online: 16 August 2012

(C) Mathematics Education Research Group of Australasia, Inc. 2012

\begin{abstract}
Issues arising in the transition from secondary school to tertiary mathematics study are increasingly coming under scrutiny. In this paper, we analyse two practical aspects of the school-tertiary interface: teaching style; and assessment. We present some of the findings arising from a 2-year national project in New Zealand titled "Analysing the Transition from Secondary to Tertiary Education in Mathematics" supported by the New Zealand Ministry of Education. The results provide evidence of similarities and differences between teachers and lecturers in their preferred teaching approaches and assessment strategies that contribute to a transitional gap between the school and tertiary sectors. The results also show that each group lacks a clear understanding of the issues involved in the transition from the other's perspective, and there is a need for improved communication between the two sectors.
\end{abstract}

Keywords Transition $\cdot$ Teaching $\cdot$ Assessment $\cdot$ Secondary $\cdot$ Tertiary

\section{Introduction}

The growing importance of the teaching and learning of mathematics to a knowledge economy has led to a worldwide interest in issues arising in the phase of transition from school to university. Possible problems in this transition have been identified, with de Guzman, Hodgson, Robert, and Villani writing that “...the secondary-tertiary transition can be seen as a major stumbling block in the teaching of mathematics" (de Guzman et al. 1998, p. 748). Perceived problems inherent in this transition include

\footnotetext{
M. O. J. Thomas

Department of Mathematics, The University of Auckland, Private Bag 92019, Auckland 1142,

New Zealand

S. Klymchuk $(\bowtie)$

School of Computing and Mathematical Sciences, Auckland University of Technology,

Private Bag 92006, Auckland 1142, New Zealand

e-mail: sergiy.klymchuk@aut.ac.nz
} 
international concerns about decreasing numbers of students opting to study mathematics at university and beyond (e.g., the ICMI Pipeline Project), and apparent decreasing levels of competence (Smith 2004). It seems that although mathematics in high school enjoys a special position in the curriculum, the knowledge and skills of incoming university students may not echo this fact (Artigue 2001). One aspect of this is the concern expressed in the report Tackling the Mathematics Problem commissioned by the London Mathematical Society (LMS 1995), surrounding a lack of essential technical facility, a marked decline in analytical powers, and a changed perception of what mathematics is, especially with regard to the place of precision and proof. This situation is not restricted to 'new undergraduates' who 10 years ago would not have proceeded to higher education. The problem is more widespread, with concern over the possibility of a widening gap shown by studies in different countries around the world (see e.g., Brandell et al. 2008; Engelbrecht and Harding 2008). In addition, it is not just the case that some students are less well prepared, but many 'high-attaining' students may be lacking in fundamental notions of the subject such as students' procedural understanding of algebraic material (Kajander and Lovric 2004; Novotna and Hoch 2008). Such studies mention a number of possible reasons for student under-preparedness, including a recent trend of moving from elite to mass university education, lowering the mathematics standards at school and university, inadequate funding, etc.

A review of the literature produces ample evidence that the transition in mathematics is a complex problem (de Guzman et al. 1998; McInnes et al. 2000; Schoenfeld 1994; Wood 2001; Brandell et al. 2008; Wood and Solomonides 2008; Tall 2008; Clark and Lovric 2009; Engelbrecht et al. 2009). An examination of possible reasons for these difficulties suggests that a number of changes occur in the transition to tertiary education, including those in teaching and learning styles, type of mathematics taught, conceptual understanding, procedural knowledge required to advance through the material, and changes in the amount of advanced mathematical thinking needed. Hence, there is a number of ways in which the possible causes of the problems in transition may be classified. Some of these appear to be related to students, some to teachers and lecturers, some to mathematical thinking itself and others to societal or institutional factors. In this paper we focus on the teacher and lecturer issues of teaching style and assessment practice.

While teaching style is clearly about pedagogy, the literature also addresses the content knowledge of teachers. The notion of mathematical knowledge of teachers (Ball and Bass 2000, 2003; Hill and Ball 2004) extends Shulman's pedagogical content knowledge, by combining three kinds of subject matter knowledge with three kinds of pedagogical knowledge. Ball and Bass believe that it is important that teachers make use of their mathematical knowledge to bring about "pedagogically useful mathematical understanding" (Ball and Bass 2000, p. 89). To achieve this: "[When they] meet novel situations in teaching, teachers must bring to bear considerations of content, students, learning and pedagogy. They must reason, and often cannot simply reach into a repertoire of strategies and answers" (ibid, pp. 88-89). Hence, by utilising their mathematical knowledge, teachers and lecturers can focus on improving students' learning.

One factor influencing teaching style and assessment practice is the mathematical under-preparedness of students entering university (Hourigan and O'Donoghue 2007; 
Kajander and Lovric 2005; Luk 2005; Selden 2005). This lack of preparedness is not confined to low-ability students. For example, an Irish study carried out by Hourigan and O'Donoghue (2007), found that $31 \%$ of high performing A-grade students appeared to be unprepared for tertiary mathematics. According to the report Measuring the Mathematics Problem by Hawkes and Savages (1999) the situation in the UK has been exacerbated by "...a combination of syllabuses, style of examination questions, marking schemes and their implementation-above all the mathematical experience they bring with them" (p. 17), bringing assessment clearly in to the picture. Another report, by the London Mathematical Society, Tackling the Mathematics Problem (1995) commented on "increased in-homogeneity in mathematical attainments and knowledge of students entering science and engineering degree programme" (p. iii) and highlighted the trend of declining diagnostic results in various tertiary institutions over the past decade indicating poor basic mathematical skills. Of course some argue that a gap between school and university is unavoidable or is not necessarily a bad thing (Clark and Lovric 2008, 2009; Wood and Solomonides 2008). They point out that the culture of schools and universities are usually quite different. Certainly the separation, liminal or transition, and reincorporation stages in the process of moving from one culture to another (Clark and Lovric 2009; Taylor et al. 2007) provide their own challenges for students. Our view is that the existence of demanding aspects of transition that are difficult to control is not in itself a good enough reason to ignore those that can be managed to produce a better experience for students. In summary, although the publications discussed in this section touch different aspects of the transition they have one thing in common - they produce an awareness of the transition period and the desirability of smoothing it.

\section{Teaching and learning in transition}

Apart from institutional variables the next major influence on teaching style is probably the orientations, or dispositions, beliefs, values, tastes and preferences, etc., that the teacher or lecturer brings to bear on their pedagogical practice. The role of such orientations has been examined in detail by Schoenfeld $(2008,2010)$ leading to a framework that may be used to analyse teachers' in-the-moment decisions. The framework involves describing the complex, ever-changing set of Resources, Orientations and Goals involved in the production, prioritisation and accomplishment of goals. The theory suggests that teaching starts with the orientations the teacher brings to their pedagogy, and these then shape the goals and their priority (Schoenfeld 2010, p. 29) Mental and physical resources are then applied to attain achievement of these goals. One such knowledge resource is clearly the content knowledge of mathematics, but another example would be the common routine named the IRE sequence, where one initiates an interaction (I), gets a response (R) from the class or an individual, and then evaluates (E) it. Schoenfeld's framework has been used in research to identify how beliefs about the nature of teaching, learning and mathematics can influence teacher practice, including goal setting (Aguirre and Speer 2000). In addition, Törner et al. (2010) use it to describe how subject matter goals and beliefs can dominate pedagogical content goals and beliefs. Hence, in this research, we 
sought to obtain data on the beliefs and goals of lecturers (and students) and whether these influence teaching style and assessment practice.

The mathematics curricula and aims of schools and universities are also different. One aspect of this is a qualitative change in the kind of thinking required to succeed. It has been hypothesised that a major reason for the gap between school and university mathematics is precisely this. Research has shown that mathematics students from UK (Hoyles et al. 2001), Hong Kong (Luk 2005) and Ireland (Hourigan and O'Donoghue 2007) tend to adopt a surface learning approach in schools but are expected to apply deep learning in tertiary mathematics. Many students are exposed to a formal deductive approach in mathematics for the first time only upon entry to university and may therefore experience a significant amount of cognitive conflict in their first year. "At school the accent is often on computations and manipulation of symbols to 'get an answer', using graphs to provide imagery to suggest properties, while at university there is a bifurcation between technical mathematics that follows this style (with increasingly sophisticated techniques) and formal mathematics, which seeks to place the theory on a systematic, axiomatic basis" (Tall 1997). One possible reason for the school emphasis, according to Hourigan and O'Donoghue (2007) is the examination-oriented nature of the school educational system that tends to promote a faster pace of teaching, and routine mastery of algebraic procedures. Consequently, surface learning is seen as a fast and workable solution in schools, but may create a culture of learning that fails to prepare students for tertiary level mathematics. An international study by Gruenwald et al. (2004), which considered university lecturers' perspectives on the transition, supports this conclusion. According to the participants' responses in this research the two main reasons for the gap between school and university mathematics were "a higher level of thinking at university compared to school and a strong emphasis on passing examinations at school" (2004, p. 15). The study also discussed a variety of the existing practical remedies that can help to bridge the gap and possible ideas for smoothing the transition period.

Tall's developing theory $(2004,2008)$ suggests that mathematical thinking exists in three worlds, the embodied, symbolic and formal. The embodied is where we make use of physical attributes of concepts, combined with our sensual experiences to build mental conceptions. The symbolic world is where the symbolic representations of concepts are acted upon, or manipulated, where it is possible to switch from processes to do mathematics, to concepts to think about mathematics. The formal world is where properties of objects are formalised as axioms, and learning comprises the building and proving of theorems by logical deduction from these axioms. If tertiary courses are trying to build thinking in the formal world with students who have been primarily symbolic thinkers at school, then difficulties will necessarily arise. This theory suggests a structure for different kinds of mathematical knowledge and how they relate to each other, and so links in to the content knowledge side of the concept of mathematical knowledge for teaching, mentioned above.

It is Tall's (1991a) contention that during the difficult transition from pre-formal mathematics to a more formal understanding of mathematical processes students need explicit assistance to gain insight into concepts. This agrees with the American school standards (NCTM 2000) and Ma (1999), who have argued that a deeper understanding of why mathematical ideas work, rather than just how, is crucial to retention and 
long-term understanding (which is an essential factor in narrowing the transition gap). Specifics of transition in terms of understanding definitions of several concepts in mathematical analysis have been addressed as well (Alcock and Simpson 2002). In particular, the authors found that "one reason for the difficulty of the transition to university mathematics is that certain reasoning strategies are inadequate when applied to university mathematics, although they may be efficient and successful in non-technical contexts and in the kind of reasoning with specific objects required by school mathematics" (ibid, p. 33).

One major issue arising from this is that students in transition are likely to face immense "cognitive conflict" when they encounter advanced mathematics if they adopt surface, procedural learning in school. This has been recognised by Tall (1991b, p. 251), who observed that "The formal presentation of material to students in university mathematics courses - including mathematics majors, but even more for those who take mathematics as a service subject-involves conceptual obstacles that make the pathway very difficult for them to travel successfully."

Based on his understanding of the conflict students often face in transition, Tall (2008) has developed a theoretical framework of three worlds of mathematical thinking that addresses this issue. He focuses on the need for teachers and lecturers to understand students' 'met-befores', or current processes and concepts that are strongly held and based on specific prior experiences, since this will assist in clarification of expectations of students. These "'met-befores' can operate covertly, affecting the way that individuals interpret new mathematics, sometimes to advantage, but sometimes causing internal confusion that impedes learning" (Tall 2008). Hence, tackling these is especially important for students in transition, when, during the incorporation period of tertiary learning, the lecturer may need to tailor teaching so it is more consistent with the school mathematical learning experience. Informed by the research background described above, this paper analyses two factorsteaching style and assessment - that seem to contribute to a transitional gap in mathematics education between the school and tertiary sectors and suggests possible remedial action.

\section{Study design and methodology}

This research employed a survey, interviews and lesson observations. The whole population of New Zealand schoolteachers and first-year tertiary lecturers who teach calculus was surveyed, using questionnaires. In addition, those who agreed were interviewed and there was also some observation of school lessons and tertiary lectures. We also surveyed and interviewed a focus group of students.

Parallel questionnaires were sent to all 350 secondary schools in New Zealand to be completed by all teachers who teach calculus in Years 12 or 13 (age 17-18 years) and to the 31 Tertiary Institutions (Polytechnics, Universities and Institutes of Technology) in New Zealand to be completed by all the lecturers who teach first-year calculus, or teach in courses with calculus components. The questionnaire included 68 questions in five sections - institution details, mathematics department calculus teaching, personal calculus teaching, opinion on calculus teaching and personal details. The questionnaires were posted, complete with a stamped addressed return 
envelope, and potential respondents were given 3 weeks to answer. After this, a follow-up copy was sent by email to remind the teachers and lecturers to reply. Using this approach, we received a total of 178 teacher and 26 lecturer responses. Since there are no figures available on the total number of calculus teachers in New Zealand schools, which vary in size from fewer than 30 students (small country school) to 3,000 (inner city), we can only estimate the response rate at about $30 \%$ of that population. The position is similar with regard to tertiary lecturers. In our opinion, the response rate was satisfactory and comparable with other response rates in mathematics education research that involve self-selected sampling and a comprehensive questionnaire. In addition, we also surveyed 77 students, 35 of whom were both at school and taking a university course, and 42 who were in their first year of tertiary studies. The former group, although still at school, was simultaneously taking a firstyear university paper involving calculus. We considered that the thoughts and experiences of this group of students would be particularly useful in forming an opinion on any transition difficulties. We took into account that the group was special in the sense that most of the students were expected to major in mathematics. Each participant in the survey was given the option of whether they would like to be interviewed. Those agreeing filled in their contact details at the end of the questionnaire enabling 6 lecturers, 16 teachers and 11 students to be interviewed. The interviews were about 60 min long on average. The participants gave more detailed responses to questions similar to those from the questionnaire during a relaxed conversation. Those teachers and lecturers who were interviewed were then asked if they would be willing to have their teaching observed. This resulted in the teaching observation of two lecturers and four teachers (covering five classes). To support conclusions, we quote from the most common participants' responses to certain questions. In cases when a comment was exceptional we indicate that. In most cases, we do not differentiate comments made on the questionnaire from those at the interviews because the interview questions were closely related to the questionnaire.

\section{Results}

Teaching style

Although the mathematical culture of school and university differs, there were many similarities between teachers and lecturers in terms of their style of teaching calculus. For example, $92.6 \%$ of teachers and $87.6 \%$ of lecturers "often" or "usually" use instruction from the front of the room. In addition, low numbers used investigative group work; $7 \%$ of teachers and $6.3 \%$ of lecturers. However, $34.7 \%$ of teachers use general student group work, and, interestingly, so do $33 \%$ of the lecturers. The difference between these last two modes is noteworthy since it implies that in both groups similar numbers (around a third) are happy for students to work in groups, but that the students are likely to be working on exercises of some kind rather than carrying out investigations. This agrees with the percentages using teacher exercises on the blackboard or worksheet, 63.9 and $86.7 \%$ for teachers and lecturers, respectively.

Despite the above agreement in practice, there were some differences in engagement in teacher-student discussions ( $72.8 \%$ of teachers versus $43.1 \%$ of lecturers) 
and use of textbook exercise work $(80.5 \%$ of teachers versus just $18.8 \%$ of lecturers). The lower level of these in lectures implies withdrawal of important tools that contribute to a learning discontinuity for students.

As well as addressing practice, we also used questions to elicit beliefs about mathematics (calculus) and how to teach it. Teachers and lecturers expressed broadly similar views on the importance of teaching the following aspects of calculus (percentage shows those teachers and lecturers, respectively, saying they are important to teach): concepts-98.3 and $92 \%$; applications-84.8 and $92 \%$; students' understanding of the practical value of calculus -80.6 and $72 \%$; gaining mathematical thinking skills (reasoning, justification, proof) -95.3 and $76 \%$. Proof seldom appears in the school curriculum but the final figure of $95.3 \%$ of teachers saying that it is important (more than the lecturers) suggests that this is an area that curriculum designers need to address.

There were some differences between the two groups in the perceived importance of teaching the following: modelling-88.1\% teachers versus $48 \%$ lecturers; communication skills- $89 \%$ teachers versus $36 \%$ lecturers; factual knowledge, procedures, algorithms, techniques - $82.6 \%$ teachers versus $44 \%$ lecturers. Interestingly, the number of lecturers valuing modelling and procedures and algorithms is lower than expected, but the low importance placed on communication skills is not. Forty-one out of 64 teachers $(64.1 \%)$ who commented on differences in interaction between school and university reported their belief that there is less interaction and communication with students at tertiary level:

Less personal interaction with students;

Suspect that teacher-student communication would be considerably less at tertiary level.

Questions on factors influencing students in transition produced comments about class size, and mode of delivery making communication more difficult. However, there were also teacher comments that tertiary students are expected to be more 'independent' and take 'more responsibility for their learning', as shown below.

Large course sizes at university prevention interactive investigative approach to new material. Difficult for students to ask questions.

Bigger classes and lectures.

More lecturing rather than teaching.

More lecturing and less time to 'do' problems at tertiary level.

Students are more independent at university and teacher-student communication is high at school.

Tertiary students are taking more responsibility for their own learning. Teaching style is more teacher-centred.

Another important consideration of teaching is whether it promotes surface or deep learning, has a procedural or conceptual emphasis. The Likert subscale on the teaching of calculus from section 5 of the questionnaires given to teachers, lecturers and students (with small wording changes) considered the approaches employed, 
with statements such as: 'Being able to differentiate and integrate is more important than understanding the concepts of differentiation and integration', and 'I favour the frequent use of applications of calculus in my lessons'. Overall both teachers and lecturers were neutral with regard to emphasising procedures over concepts (teacher mean 3.09; lecturer mean 2.95), although students (mean 2.86) thought their teaching slightly procedural. Teachers (mean 2.10) and lecturers (mean 2.09) both disagreed that doing is more important than understanding in differentiation and integration. All three groups agreed on the importance of using lots of examples (teacher mean 3.43; lecturer mean 3.77; student mean 3.55), the value of applications (teacher mean 3.77; lecturer mean 4.17; student mean 3.71), as well as the value of graphs to reinforce concepts (teacher mean 4.07; lecturer mean 4.13; student mean 3.86).

It seems that teachers perceived tertiary lecturers as promoting deep understanding and learning, in contrast with many teachers' tendencies to promote surface learning through a drill and practice mode of teaching. In the interviews, many teachers commented that drill and practice combined with teacher correction of errors would help their students to apply their skills based on the examples taught in class. This immediately shifts the onus of learning to the students. In most cases, they believe that learning is about skill application and algorithms. Some of their common comments were:

T010 I give my students feedback by asking them to do assignments and give them written feedback on what they've managed to do, and the steps they need to take to get to where they need to be. I give them feedback from their classroom work by looking at their exercise books after lessons and commenting on it. ... they do practice some skill from the day before or some idea they represent it, and so most of the feedback is either in oral or written form.

T132 They work and then I mark. I don't talk too much; they do everything, I mark. ... So that's what we are concentrating on at the moment, to practise and practise - and even sometimes I give the same paper and they can't do it.

T159 I tend to use that quite a lot, and I get the students to work through them with me, or instead of me, but I think that in many ways part of the analytical process is recognition of a type, and therefore if they have got some examples of how to approach a certain question, what we're expecting them to do is take the skills that they have from these worked examples and adapt them to a new situation.

Apart from its role in giving constructive feedback, one teacher strongly believed that going through examples in class aids understanding of mathematical concepts.

T145 It's the easiest way of getting across to kids; to go through examples that they can follow cements their understanding. From one to ten I would rate them [examples] as a nine.

Whether promotion of surface learning by teaching focussed primarily on using examples is more widespread among teachers than lecturers remains to be confirmed. Even though the survey showed that fewer lecturers perceived algorithms as important, it was evident from their interviews that some lecturers tended to support learning through repetitive practice. 
L015 Usually after I have done a couple of examples, even though I will be doing it in front of the class, I usually get students to fill in the gaps for me and then I give them a lot of questions to work on in class and I go around and try to help them as well.

L023 I had to talk to 3rd year students about study skills, and tell them that they really need to practice examples. Perhaps you can talk to your mates about what works for you and how you learn best. If you can solve a problem without looking into the book on how to do it, then you understand, and know, the material.

L023 You have to do a problem several times with different numbers to show the students the theory involved.

In Q22 of the survey (Do you think that there are differences between Year 13 and first-year tertiary calculus teaching in any of the following areas? If so please describe them), teachers and lecturers were specifically asked if they thought that there were differences in the following areas: $\mathrm{A}$-assessment, $\mathrm{B}$-teaching style, $\mathrm{C}$-teaching resources, D-teaching emphasis, E-technology use, F-teacher preparedness, and G-students' experiences, and if so, why.

An overview of the teachers responses is summarised in Fig. 1. While there are perceived differences of more than $30 \%$ in assessment, teaching style, teaching resources and student experiences, the most common response from teachers to whether there are any differences was "don't know". This could be an issue when considering the transition from school to tertiary study since it implies a lack of knowledge of the tertiary situation. Three teachers alluded to possible reasons for this in their interviews, including a lack of feedback from universities.

T018 I think that we don't.. we haven't got a lot of uniformity amongst schools in presenting to students what to expect at university, and I don't think the universities do that brilliant a job in feeding back to schools what they want...I do believe that, where schools are trying to find out what's required at university.

T010 I think it would be really useful from my point of view to actually meet with a lot of the people who get our students, and say to them 'what are the things that we are doing that are really good and what are the things that you would like us to do more of?'

T146 I wouldn't know. The task of a secondary school is to follow the curriculum. Occasionally I would divert and teach something slightly different, beyond the curriculum, but I don't do it often.

In each of these areas, fewer than $10 \%$ of the teachers reported there was no difference. There was no significant difference between the number of teachers and lecturers who thought that there were differences in teaching style $(50.7 \%$ of teachers and $65.4 \%$ of lecturers, $\chi^{2}=1.93$, n.s. $)$, but there were significantly more teachers than lecturers who said they did not know whether there were any differences $\left(\chi^{2}=\right.$ $14.74, p<0.001)$. The prevalent perception of differences in teaching styles was that the level of interaction between lecturers and students at tertiary level is not sufficient 


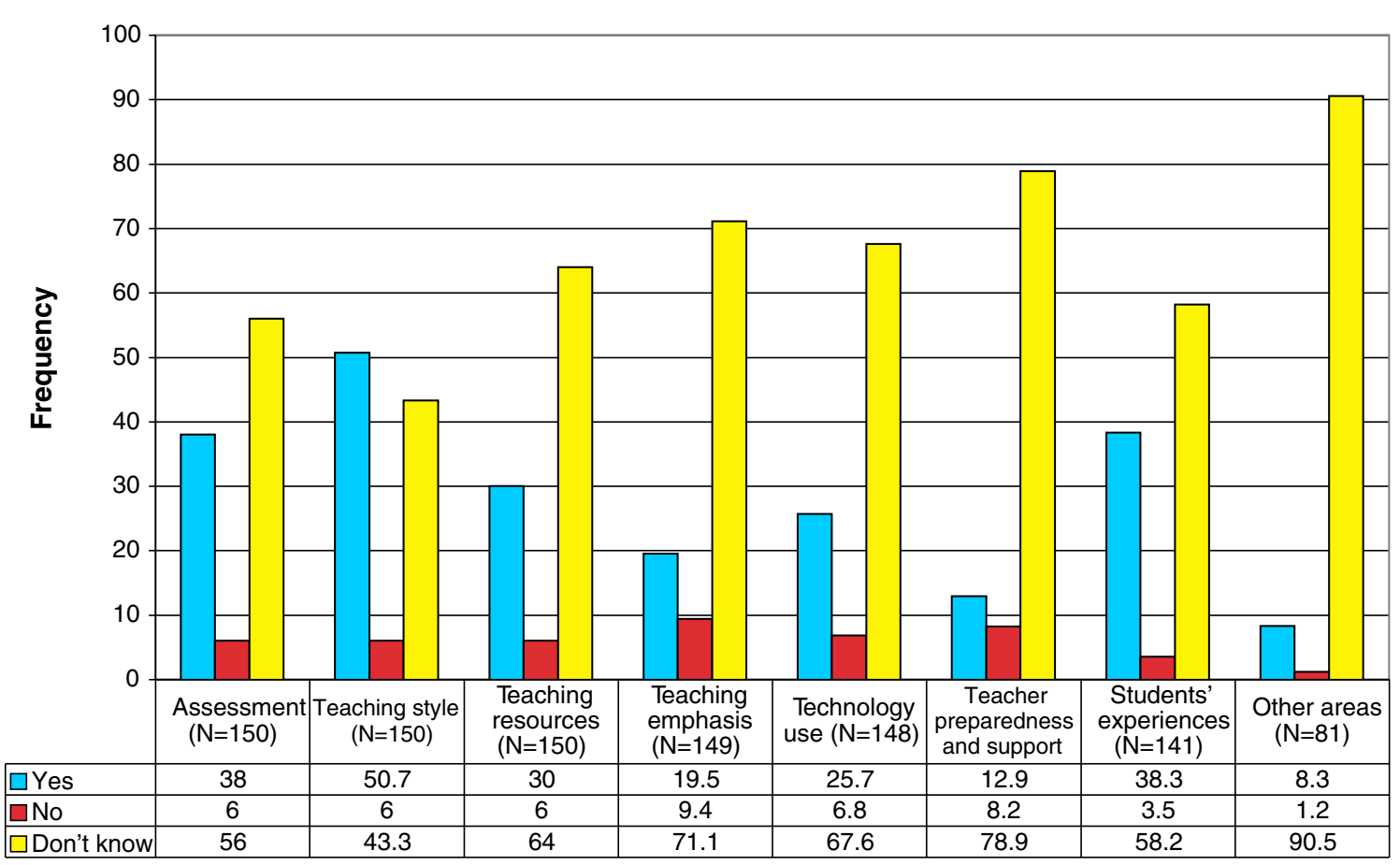

Fig. 1 Percentage of teacher responses for each part of Q22

(41 teachers, $64.1 \%$ of 64 responses; 10 lecturers, $80 \%$ of 13 responses-see above). The lecturers' comments often agreed: "Primarily lecture format less interactive than school" (L002) and "Teaching style more formal less individualistic" (L003). That this is seen as due to large class size is evident from comments such as, "my class is 420 students! Determine style" (L008) and "Lecture style is all one way for large 200+ classes" (L013). These observations are consistent with many teachers' views, such as "Tertiary students are taking more responsibility for their own learning. Teaching style is more teacher-centred" and "Less personal interaction with students", but this view was also tempered with: "Attendance at tutorials at university may alleviate or moderate the 'clinical' nature of lecturing."; "Large course sizes at university prevent interactive investigative approach to new material. Difficult for students to ask questions"; and "More lecturing rather than teaching." Other observations included, "Teaching is more detailed in Year 13 than in the first-year tertiary calculus" and "More technology and lecturing" at tertiary level. Teacher indications in the questionnaire and the interviews were that the communication between them and the students was of paramount importance.

There were significantly more lecturers than teachers who thought that there were differences in teaching emphasis $\left(\chi^{2}=12.53, p<0.001\right.$ ). However, $71.1 \%$ (of 149 responses) of the teachers answered that they did not know of any differences in teaching emphasis between school and tertiary level, significantly more than the number of lecturers who said they did not know $\left(\chi^{2}=36.3, p<0.001\right)$.

Similarly, $52 \%$ of the lecturers agreed with the teachers' view that lecturers "focus on understanding concepts rather than learning techniques" and place an emphasis "on applications in particular areas, example engineering, science". In the survey lecturers were given Likert scale questions asking what they consider important $(1=$ Not important to $5=$ Very important) when teaching calculus. In particular, the results showed that $92 \%$ (rating 4 or 5 ) value the learning of concepts and applications in calculus teaching (although only $40 \%$ valued new applications). Further, $88 \%$ 
thought students should gain problem solving skills, $76 \%$ that they should enhance mathematical thinking skills and $72 \%$ that students should both do exercises from the manual and see the practical value of calculus. On the other hand, only $28 \%$ thought it important that students work together, $36 \%$ that they should develop communication skills, $44 \%$ valued factual, procedural or algorithmic techniques and $48 \%$ thought that students should gain modelling skills. These results seem to support the contention that concepts, mathematical thinking, applications and problem solving are seen as more important at tertiary level than procedures, modelling, collaboration and communication. In contrast this latter group is often what is emphasised in schools.

Students' perspective on teaching Forty-nine out of the 63 students $(77.8 \%)$ who responded reported that there were differences in teaching style and/or emphasis between school and tertiary level. Of these, 42 commented on teaching style, with $21.4 \%$ noting less interaction, and $23.4 \%$ a faster pace, at tertiary level.

We record below some of the more interesting comments made by high-achieving students who were attending both Year 13 and tertiary Calculus courses at the same time. We note that the experience of these students does not directly mirror that of a typical first-year student. While one of their lecturers also taught on the standard course first year, they were in a class of around 80, rather than 150, and had one evening lecture of $2.5 \mathrm{~h}$ per week rather than the standard $3 \mathrm{~h}$ of lectures and one tutorial for such students. Nevertheless, we consider them to be in a good position to compare the teaching at both school and tertiary levels.

The vast majority of these very good students preferred the university mathematics, seeing it as better organised and more logically structured with fewer routines, more challenging problems, and greater depth, as seen in the comments below.

S003 Studying pure maths affected the way I think about maths. Learning mathematical definitions, for example, allowed me to understand and appreciate maths better than I did at high school level, where I simply learned different topics and how to solve different problems. Maths at high school wasn't structured logically.

S003 At high school the style was skills-based; at tertiary level there was more scope for me to look at concepts as a whole, and after a while everything clicked into place.

S044 ... with school math, I don't particularly like it but I've got no problem with it. I do it and I do pretty well in the exams, and I do most of my homework, but the reason I like math is more to do with the Olympiad style and the uni style of math where I can just learn whatever I want, sort of go into more depth to be honest, and not being spoon-fed.

S044 I think that's because the school syllabus doesn't go into enough depth, and if someone's going to do math in uni anyway, then they should learn things properly in high school, I think that's quite important. Not necessarily deriving everything from first principles but sort of - I think the syllabus should do more explanation that just saying, well, here's the formula, learn it. 
However, some students found the depth of university mathematics harder and more challenging, with the result that they did not enjoy it. One exceptional comment is presented below.

S033 I get a high score but I didn't actually enjoy maths at university because university maths was a little bit harder than high school maths, and the way of solving problems and approaching to solve problems was actually different because at high school we just needed to solve it, we just used a formula and if we know the formula we could solve it. But at university we have to prove something and proving something was much more difficult than solving just a simple question.

Clearly students' preferences in teaching and learning style vary depending on their ability level and attitude. The students who were studying at both school and university were mostly very capable students, and these appeared to prefer the university's approach to the school one.

\section{Assessment}

In the responses to Q22 on the survey, which asked 'Do you think that there are differences between Year 13 and first-year tertiary calculus teaching in any of the following areas? If so please describe them', there was no significant difference overall between the number of teachers and lecturers who answered that there were differences in assessment $\left(\chi^{2}=3.55, p<0.1\right)$. Similar proportions of teachers and lecturers admitted that they tend to teach to the assessment (34.5 and $30.4 \%$ respectively). This was confirmed by responses to the five-point Likert scale question on teaching to the assessment (teacher: I tend to teach to the external assessment in calculus; lecturer: I tend to teach to the assessment in calculus), although more lecturers (12 out of $23,52.1 \%$ ) than teachers (59 out of $171,34.5 \%$ ) appeared to "agree" or "strongly agree" with the statement. Teachers who went on to comment about differences in assessment between school and tertiary level made observations such as, "A lot more assessment" (4, 6.1\% of 66 comments), although it is not clear whether they felt that school or tertiary had more. References were made to the differences in assessment styles, such as "Standards-based versus norm-referenced" $(4,6.1 \%)$ and "Presumably universities are not using the type of marking used in NCEA [national] exams." (2, $3.0 \%)$. There were a few comments about the use of technology in assessment: "Emphasis on no calculator use in tertiary calculus." (2, $3.0 \%$ ); and "University has computer lab sessions and assignments done using computers." There were also differences in the teacher perception of relative difficulty, "Easier to achieve at a top level at university than at NCEA level 3"; "University level is a bit more challenging"; and "Some topics requiring higher skills and extra topics such as matrix and learning how to solve using Matlab." In the interviews, teachers talked at length about assessment in the National Certificate of Educational Achievement (NCEA) and the attitudes of students and themselves in dealing with this summative assessment. A theme of tailoring work to assessment at a specific, often lower, level was prevalent: "The type of questions I give them is similar to that they will receive in an exam or an assessment" (T145); "I think that the 
internal assessments... because you know what you're going to be assessing them and because of time constraints, you can teach the content that's in the assessment. I'm afraid that that's the sort of thing that has crept in." (T156); and "Let me think of an example, let us go back to my expectations with the majority of the class, if I'm aiming at achieved or merit I might skip out the excellence part work at the end." (T134).

In contrast, some lecturers presented a vague understanding of school assessment in terms of the type and how they are graded compared with tertiary practice: "No assignments at school" (L001); "Must pass regular basic skills test (without crib sheets, etc.) and finals examining a broad range of topics" (L004); and "Formal exams" (L005). On the other hand other lecturers were clearly aware of the NCEA school system, and were able to make comparisons: "NCEA does not require a student to get 'more than half' correct to pass (achieve)" (L010); "Assignments differ from NCEA internal assessments" (L003); and "Not so vigorously 'standard based'. Marks are given for partial and partially correct answers" (L011). In terms of grading, these statements by L010 and L011 may suggest the lecturers perceived students achieve a lower level of performance because of the standards-based marking in NCEA examinations, whereas at tertiary level they expect all working to be shown to pass the examination, and students gain credit for all they do.

In relation to the role of assessment in teaching and learning of calculus many teachers made concerned comments about aspects of the NCEA standards-based assessment system, as well as the need for formative assessment. However, the majority of the teachers agree that assessment is important:

T043 Internal assessments use up a vast quantity of time and it's obviously cheap but whether it's educationally sound is a completely different question.

T119 There's two kinds of assessments; there's formative assessments and summative assessment. Now. The kids place a great deal of assessment on summative assessments because it is what's going to get them into university. And so consequently we have got to pay a lot of attention to that. And we have to make sure that they reach the required level. Formative assessment is important too for your teaching. If you don't use it you are missing out on so much.

T159 The disturbing fact is that the method of assessment through standardsbased assessment, ...there's no facility for showing your understanding because we treat the person who did not attempt an excellence question, we give them exactly the same assessment the person who got nine tenths of the way through a really involved complex process, and they get the same level of assessment at the end of it...I strive to maintain assessment as something I focus on at the end of the learning process, but again I'm increasingly being pressured through the NCEA environment to focus on the assessment at the beginning and work towards that, which is very detrimental.

On the other hand, some teachers expressed concerns that their students are overassessed, especially in internal assessment, and were frustrated, feeling that time spent on assessment could be better spent on teaching. 
T010 With the number of internal assessments we have and the number of credits that the students have to have delivered to them, the assessment is driving what we do more than I would like to see it, so I think the role of summative assessment is far bigger than ideally it should be.

T039 It's great that you can do some internal assessments. ... A standard basic internal assessment is not relevant to an academic subject. ... Because now what's happening with NCEA is they are changing all their standards so all this work the teachers have done-preparing materials, getting resources, toss it out and start again. Ok you can use some of the stuff because maths is maths. But it's hugely frustrating and time consuming.

There were also some concerns that students tend to learn to pass examinations and that teachers simply teach them how to pass them.

T145 With NCEA, kids unfortunately only want to learn something if it will be assessed... Kids look at the number of credits and how to get them, as opposed to having a long-term view of investment in education for the following year. It is important for the kids to have goals; they are learning to pass exams.

T156 I think that the internal assessments because you know what you're going to be assessing them and because or time constraints, you can then teach the content that's in the assessment... why bother teaching that when you know it's not in the internal assessment.

Lecturers definitely have more control, and hence flexibility, over assessment and they may try different strategies, like those mentioned below. Generally, their comments about the assessment were more positive than those of teachers.

L005 It provides an enormous amount of feedback to me. It provides an enormous feedback to the students. It breaks the confidence of a number of students. ... So it has a motivating effect to some extent... Beyond that fear barrier, it's certainly useful.

L018 There is large element of what we teach and how we teach that is driven by the assessment and what is expected of it. I think assessment should be designed to support the students learning as opposed to the other way around ... I believe that the talking about mathematics and discussing it in groups and looking at it from a problem solving based approach is a valuable thing for students to learn how to do...I would put far more emphasis and less weight on the exam if I had the choice.

L023 Assessment is for grading people and for giving people feedback and see how they are going, whether they need to try harder.

Students' perspectives on assessment About two thirds of the students (40 out of 63 or $63.5 \%$ ) reported that there is a difference in assessment practice between school and tertiary institutions. The vast majority of the students who were interviewed mentioned that they found the assessment at tertiary level much better and more efficient than at school level. Some of the differences in assessment at university 
included: no hierarchy of questions; questions being more to the point; more frequent assessment; the need to gain marks through precision in solutions; and the greater originality of question type. In particular a major difference is the marking of examinations, since most secondary schools use both unit (internal) and achievement (internal/external) standards as part of the NCEA system of assessment, which requires students to meet one of the achievement levels (achieved, merit or excellence) in various areas of mathematics. On the other hand, the tertiary institutions tended to use norm-referenced assessments such as tests, coursework and final examinations. Some of the typical student comments were:

S003 In terms of assessment there are quite significant differences. At secondary school there is the hierarchical style of questioning...the final questions are the most difficult ones and I would check the 'excellent' level question several times after finishing the assessment. At tertiary level you don't have as much time to go over questions, and also all questions are marked equally.

S014 At high school there were achievement standards that were tested periodically throughout the year, some were tested in the classroom and some at the end of the year as part of an exam. The time in the classroom was spent preparing for these tests. At university the assessments happened every week, little weekly assessments contributed to the final grade, as well as two tests that happened during the semester and an exam. The assessments at university were more frequent than at high school. It was more beneficial.

S038 One of the biggest differences between school and uni was the method of assessment and losing marks rather than just gaining marks. Not stating things clearly was a big deal at uni but at school you could get away with it. ... With NCEA you could write an equation down and solve it and that's fine. But with our uni course anyway if you didn't state the limitations, the impracticalities of what you were doing, you got those marks docked.

\section{Conclusions}

It is acknowledged that this research has several limitations, such as the relatively low numbers of lecturers and students surveyed, and a sample biased towards higher achieving students. We also hoped to receive questionnaire responses from many more first-year students outside the focus group. However, in spite of our best efforts to obtain them by advertising in lectures at a good number of institutions, very few volunteered to complete the questionnaire. This is probably a consequence of the greater freedom that obtains at tertiary level along with the added pressure of workload. We would have liked to have conducted more interviews, but the number volunteering their time for interview and observation was likewise relatively small, and some were too far away to make the task feasible. In spite of these limitations, we believe that there are a number of useful conclusions that arise from the study. These identify important issues dealing with teaching style and assessment that may contribute to alleviating the transition difficulties experienced by many students. 
One outcome is the confirmation of a disjunction in teaching emphasis and style between schools and tertiary institutions. Examples of this perceived by the participants include a greater emphasis on modelling, practice of examples (especially textbook questions), communication skills, teacher-student discussion, collaborative work and factual knowledge in schools, while tertiary institutions place more value on conceptual thinking, rigour, applications and problem solving. In turn students found the tertiary courses deeper and more challenging.

In the area of assessment we found that the lecturers tended to have greater flexibility than teachers. Teachers expressed concerns about the importance of assessments, teaching to assessments, and the overload of internal assessment. Students reported that they found the assessment at tertiary level much better and more efficient than at school. This suggests that some students in the transition to university study of mathematics, would be assisted if their school teachers moved them toward formal world thinking by explicitly considering concepts rather than primarily emphasising symbolic world procedures (Tall 2008).

An often-repeated suggestion from teachers was that students, especially in NCEA, are simply aiming to achieve in mathematics standards rather than to gain understanding at a deeper level. This inevitably leads to teachers having a tendency to teach to the lowest level too, only including what is absolutely necessary for achieving the standard. This can cause conflict during transition since tertiary work requires deeper thinking. Hence, encouraging students to aim higher, for merit or excellence, where such thinking is necessary, would be advantageous.

The lack of knowledge and awareness of what is happening in each other's courses shows a need for closer communication between secondary teachers and tertiary lecturers, and their institutions. In turn, improved understanding of the unique nature of teaching and learning in schools and tertiary institutions could help to smooth student transition. To facilitate this would require a mechanism for greater sharing of ideas and practice between the two groups, in particular by increasing opportunities for visits in both directions between mathematics departments of schools and tertiary institutions. Encouraging construction of a process for supporting a meaningful dialogue between schoolteachers of mathematics and their tertiary counterparts will, no doubt, help improve the transition from secondary to tertiary education in mathematics.

Acknowledgments We would like to thank the New Zealand Ministry of Education for providing funding through a Teaching and Learning Research Initiative grant, organised through the New Zealand Council for Educational Research, which enabled this research to take place. We also recognise the assistance in the research project of Ye Yoon Hong, Suzanne Kerr, Johanna McHardy, Priscilla Murphy, Sue Spencer and Peter Watson.

\section{References}

Aguirre, J., \& Speer, N. M. (2000). Examining the relationship between beliefs and goals in teacher practice. The Journal of Mathematical Behavior, 18(3), 327-356.

Alcock, L., \& Simpson, A. (2002). Definitions: dealing with categories mathematically. For the Learning of Mathematics, 22(2), 28-34.

Artigue, M. (2001). What can we learn from research at the university level? In D. Holton (Ed.), The teaching and learning of mathematics at the university level: An ICMI study (pp. 237-254). The Netherlands: Kluwer. 
Ball, D. L., \& Bass, H. (2000). Interweaving content and pedagogy in teaching and learning to teach: Knowing and using mathematics. In J. Boaler (Ed.), Multiple perspectives on the teaching and learning of mathematics (pp. 93-104). Westport: Ablex.

Ball, D. L., \& Bass, H. (2003). Toward a practice-based theory of mathematical knowledge for teaching. In B. Davis \& E. Simmt (Eds.), Proceedings of the 2002 annual meeting of the Canadian Mathematics Education Study Group (pp. 3-14). Edmonton: CMESG/GDEDM.

Brandell, G., Hemmi, K., \& Thunberg, H. (2008). The widening gap-a Swedish perspective. Mathematics Education Research Journal, 20(2), 38-56.

Clark, M., \& Lovric, M. (2008). Suggestion for a theoretical model for secondary-tertiary transition in mathematics. Mathematics Education Research Journal, 20(2), 25-37.

Clark, M., \& Lovric, M. (2009). Understanding secondary-tertiary transition in mathematics. International Journal of Mathematical Education in Science and Technology, 40(6), 755-776.

de Guzman, M., Hodgson, B., Robert, A., \& Villani, V. (1998). Difficulties in the passage from secondary to tertiary education. Proceedings of the International Congress of Mathematicians, 3, 747-762.

Engelbrecht, J., \& Harding, A. (2008). The impact of the transition to outcomes-based teaching on university preparedness in mathematics in South Africa. Mathematics Education Research Journal, 20(2), 57-70.

Engelbrecht, J. C., Bergsten, C., \& Kågesten, O. (2009). Undergraduate students’ preference for procedural to conceptual solutions to mathematical problems. International Journal of Mathematics Education in, Science and Technology, 40(7), 927-940.

Gruenwald, N., Klymchuk, S., \& Jovanoski, Z. (2004). Reducing the gap between the school and university mathematics: university lecturers' perspective. New Zealand Mathematics Magazine, 41(3), 12-24.

Hawkes, T., \& Savages, M. (1999). Measuring the mathematics problem. Retrieved October 21, 2011, from http://www.engc.org.uk/ecukdocuments/internet/document\%201ibrary/ Measuring\%20the\%20Mathematic\%20Problems.pdf.

Hill, H., \& Ball, D. L. (2004). Learning mathematics for teaching: results from California's mathematics professional development institutes. Journal for Research in Mathematics Education, 35(5), 330-351.

Hourigan, M., \& O’Donoghue, J. (2007). Mathematical under-preparedness: the influence of the pretertiary mathematics experience on students' ability to make a successful transition to tertiary level mathematics courses in Ireland. International Journal of Mathematical Education in Science and Technology, 38(4), 461-476.

Hoyles, C., Newman, K., \& Noss, R. (2001). Changing patterns of transition from school to university mathematics. International Journal of Mathematical Education in Science and Technology, 32(6), 829-845.

Kajander, A., \& Lovric, M. (2004). The double cohort: preliminary research on the transition from secondary to university level mathematics. The Ontario Mathematics Gazette, 42(4), 33-36.

Kajander, A., \& Lovric, M. (2005). Transition from secondary to tertiary mathematics: McMaster University experience. International Journal of Mathematical Education in Science and Technology, 36(2-3), 149-160.

London Mathematical Society (1995). Tackling the mathematics problem. Retrieved September 1, 2009, from http://www.lms.ac.uk/policy/tackling_maths_prob.pdf.

Luk, H. S. (2005). The gap between secondary school and university mathematics. International Journal of Mathematical Education in Science and Technology, 36(2-3), 161-174.

Ma, L. (1999). Knowing and teaching elementary mathematics. Mahwah: Erlbaum.

McInnes, C., James, R., \& Hartley, R. (2000). Trends in the first year experience in Australian universities. Canberra: AGDS.

NCTM (National Council of Teachers of Mathematics). (2000). Principles and standards of school mathematics. Reston: NCTM.

Novotna, J., \& Hoch, M. (2008). How structure sense for algebraic expressions or equations is related to structure sense for abstract algebra. Mathematics Education Research Journal, 20(2), 93-104.

Schoenfeld, A. H. (1994). What do we know about mathematics curricula? The Journal of Mathematical Behavior, 13(1), 55-80.

Schoenfeld, A. H. (2008). On modeling teachers' in-the-moment decision-making. In A. H. Schoenfeld (Ed.), A study of teaching: Multiple lenses, multiple views (Journal for Research in Mathematics Education Monograph No. 14) (pp. 45-96). Reston: National Council of Teachers of Mathematics.

Schoenfeld, A. H. (2010). How we think. A theory of goal-oriented decision making and its educational applications. New York: Routledge.

Selden, A. (2005). New developments and trends in tertiary mathematics education: or more of the same? International Journal of Mathematical Education in Science and Technology, 36(2-3), 131-147.

Smith, A. (2004). Making mathematics count. UK: The Stationery Office Limited. 
Tall, D. O. (1991a). The psychology of advanced mathematical thinking. In D. O. Tall (Ed.), Advanced mathematical thinking (pp. 3-21). Holland: Kluwer.

Tall, D. O. (1991b). Reflections. In D. O. Tall (Ed.), Advanced mathematical thinking (pp. 251-259). Holland: Kluwer.

Tall, D. O. (1997). From school to university: The transition from elementary to advanced mathematical thinking. In M. O. J. Thomas (Ed.), Proceedings of the 7th Conference of the Australasian Bridging Mathematics Network (pp. 1-20). New Zealand: Auckland.

Tall, D. O. (2004). Building theories: the three worlds of mathematics. For the Learning of Mathematics, 24 (1), 29-32.

Tall, D. O. (2008). The transition to formal thinking in mathematics. Mathematics Education Research Journal, 20(2), 5-24.

Taylor, P. G., Millwater, J., \& Nash, R. (2007). Talking about transitions: the value of a conceptual approach. Paper presented at Enhancing Higher Education, Theory and Scholarship, Proceedings of the HERDSA Conference 2007, Adelaide, Australia.

Törner, G., Rolke, K., Rösken, B., \& Sririman, B. (2010). Understanding a teacher's actions in the classroom by applying Schoenfeld's theory teaching-in-context: Reflecting on goals and beliefs. In B. Sriraman \& L. English (Eds.), Theories of mathematics education, advances in mathematics education (pp. 401-420). Berlin: Springer.

Wood, L. (2001). The secondary-tertiary interface. In D. Holton (Ed.), The teaching and learning of mathematics at university level: An ICMI study (pp. 87-98). Holland: Kluwer.

Wood, L., \& Solomonides, I. (2008). Different disciplines, different transitions. Mathematics Education Research Journal, 20(2), 117-134. 